\title{
Epstein-Barr virus-associated early gastric cancer presenting as an elevated lesion
}

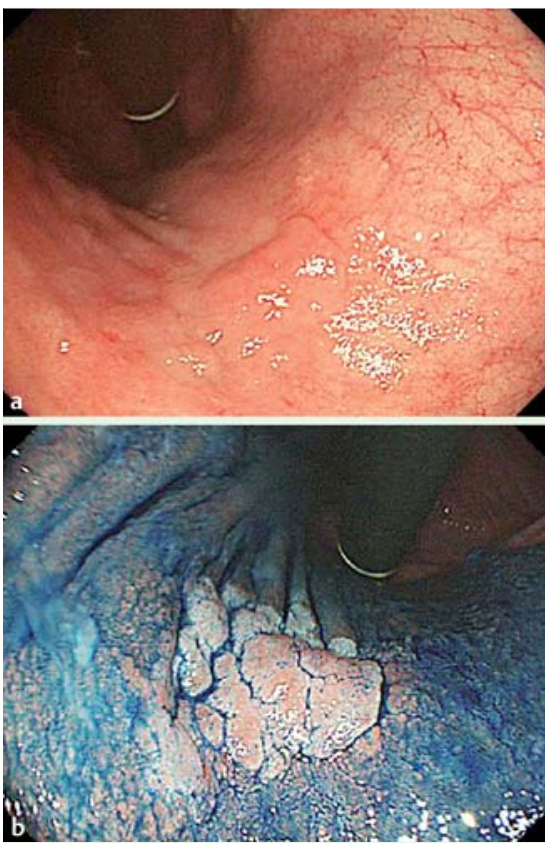

Fig. 1 Endoscopic view in a 60-year-old man showing: a an elevated lesion in the anterior wall of the middle part of the body of the stomach; $\mathbf{b}$ the same lesion after the application of indigo carmine and acetic acid with the demarcation line of the lesion clearly visible.

We report a rare case of Epstein-Barr virus (EBV)-associated gastric carcinoma that presented as an elevated lesion and was treated by complete en-bloc resection using endoscopic submucosal dissection (ESD).

A 60-year-old man was diagnosed with an early gastric cancer when he underwent esophagogastroduodenoscopy (EGD) for epigastralgia. He was referred to our hospital 2 weeks later. Endoscopic examination revealed a whitish elevated lesion of $25 \mathrm{~mm}$ in diameter, which was suspected to be an elevated-type adenoma or mucosal cancer, in the anterior wall of the middle section of the body of the stomach. The margin of the lesion was clear after the application of indigo carmine with acetic acid ( Fig.1). Endoscopic ultrasound (EUS) showed multiple rounded, hypoechoic lesions in the third layer with a slightly low-echoic mass in the first layer ( $\bullet$ Fig.2), suggestive of infiltrated lymphoid follicles or submucosal invasion.

We performed ESD as the diagnostic treatment. Histologic examination showed

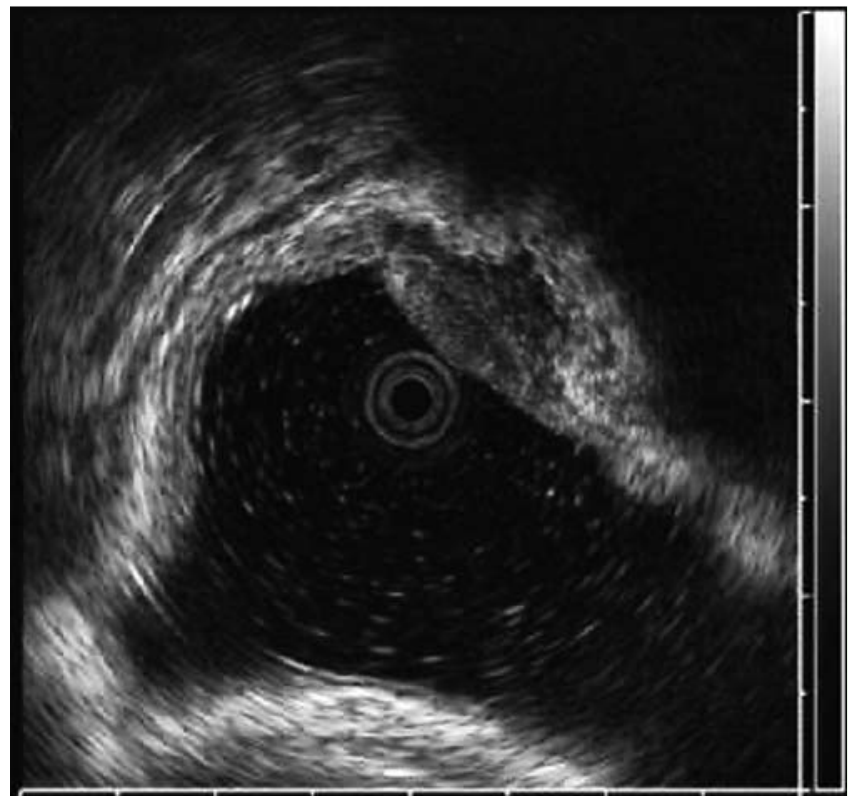

Fig. 2 Endoscopic ultrasound (EUS) image showing multiple rounded, hypoechoic lesions in the third layer, with a slightly low-echoic mass in the first layer.

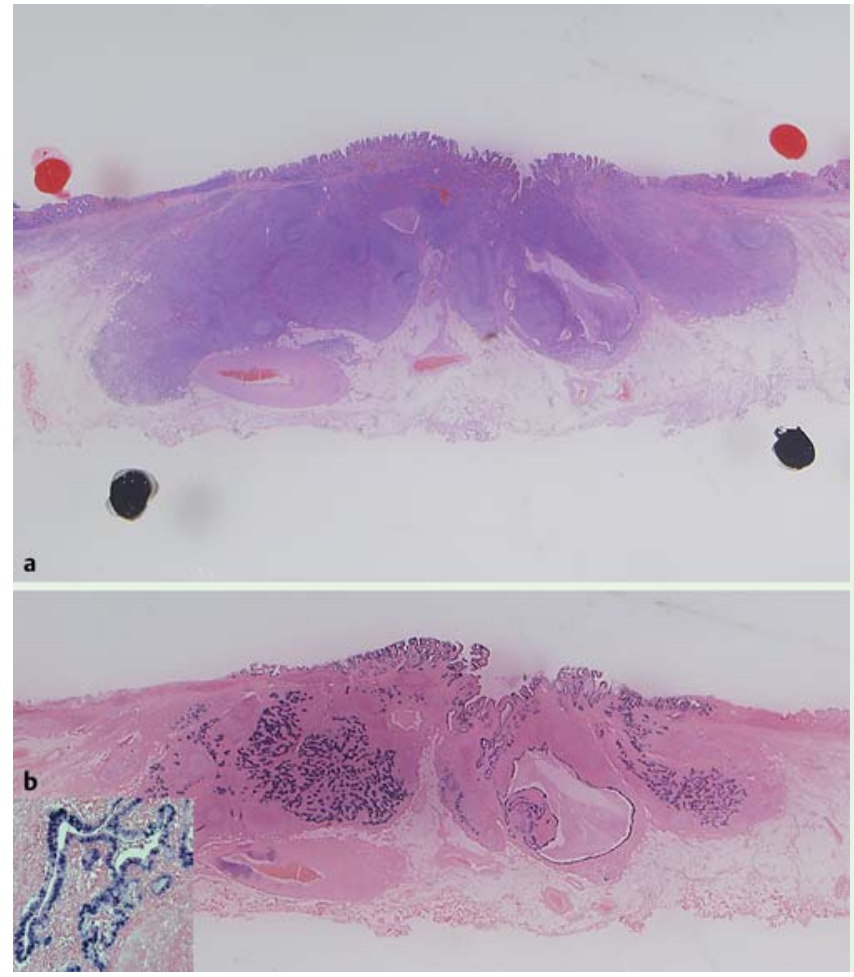

Fig. 3 Histologic appearances of the lesion. a Hematoxylin and eosin (H\&E) stain showing a diffuse-type adenocarcinoma forming submucosal nodules within the lymphoid stroma associated with intestinal-type adenocarcinoma in the mucosa. The depth of submucosal invasion was $3000 \mu \mathrm{m}$, but the lateral and vertical margins were clear (magnification $\times 4$ ). $b$ In situ hybridization for EBVencoded RNA showing strong nuclear positivity in the epithelial cells but not in the reactive lymphoid cells. Inset: High-power view.

diffuse-type adenocarcinoma forming submucosal nodules within the lymphoid stroma beneath mucosal intestinal-type adenocarcinoma. This was in line with the EUS imaging. In situ hybridization revealed strong nuclear expression of EBV-encoded RNA in the epithelial cells but not in the reactive lymphoid cells (- Fig.3). The depth of submucosal invasion was $3000 \mu \mathrm{m}$, but the lateral and vertical margins were clear.

EBV-associated gastric carcinoma makes up $4 \%-10 \%$ of all gastric cancers $[1,2]$. It often appears as depressed or ulcerated 
lesions and an elevated lesion as presented here is rare. Accompanying differentiated adenocarcinoma in the mucosa is reported to be a unique characteristic of EBV-associated gastric cancer [2]. In the present case, without EUS it was difficult to detect the submucosal invasion during EGD. EUS can be an important diagnostic tool to detect invisible submucosal structures before treatment. ESD was useful in the diagnostic treatment of this EBV-associated early gastric cancer [3].

Endoscopy_UCTN_Code_CCL_1AB_2AD_3AB

\section{Competing interests: None}

\section{S. Yamamoto, T. Nishida, M. Tsujii, M. Kato, Y. Hayashi, J. Kondo, T. Inoue, T. Akasaka, T. Yamada, K. Watabe, T. Takehara \\ Department of Gastroenterology and Hepatology, Osaka University Graduate School of Medicine, Osaka, Japan}

\section{References}

1 Yanai H, Nishikawa J, Mizugaki Y et al. Endoscopic and pathologic features of EpsteinBarr virus-associated gastric carcinoma. Gastrointest Endosc 1997; 45: 236-242

2 Watanabe H, Enjoji M, Imai T. Gastric carcinoma with lymphoid stroma. Its morphologic characteristics and prognostic correlations. Cancer 1976; 38: 232-243

3 Moon HS, Kang SH, Seong JK et al. Lymphoepithelioma-like gastric carcinoma resected by endoscopic submucosal dissection (ESD). Endoscopy 2010; 42 (Suppl. 02): E73 -E74
Bibliography

DOI http://dx.doi.org/

10.1055/s-0032-1309353

Endoscopy 2012; 44: E222-E223

(C) Georg Thieme Verlag KG

Stuttgart · New York

ISSN 0013-726X

Corresponding author

T. Takehara, MD, PhD

Department of Gastroenterology and Hepatology Osaka University Graduate School of Medicine Osaka

Japan

Fax: +81-66-8793629

takehara@gh.med.osaka-u.ac.jp 